\title{
GSTT1 Null Genotype Contributes to Lung Cancer Risk in Asian Populations: A Meta-Analysis of 23 Studies
}

\author{
Xin Yang ${ }^{1,29}$, Man-Tang Qiü ${ }^{2,49}$, Jing-Wen $\mathrm{Hu}^{1,2}$, Xiao-xiao $\mathrm{Wang}^{3}$, Feng Jiang ${ }^{1,2}$, Rong Yin ${ }^{2 *}$, Lin $\mathrm{Xu}^{2 *}$ \\ 1 The First Clinical College of Nanjing Medical University, Nanjing, China, 2 Department of Thoracic Surgery, Nanjing Medical University Affiliated Cancer Hospital, Cancer \\ Institute of Jiangsu Province, Nanjing, China, 3 Department of Bio-statistics, Georgia Health Science University, Augusta, Georgia, United States of America, 4 The Fourth \\ Clinical College of Nanjing Medical University, Nanjing, China
}

\begin{abstract}
Background: Genetic variation in glutathione S-transferases (GSTs) may contribute to lung cancer risk. Many studies have investigated the correlation between the Glutathione S-transferase T1 (GSTT1) null genotype and lung cancer risk in Asian population but yielded inconclusive results.

Methodology/Principal Findings: We performed a meta-analysis of 23 studies including 4065 cases and 5390 controls. We assessed the strength of the association of GSTT1 with lung cancer risk and performed sub-group analyses by source of controls, smoking status, histological types, and sample size. A statistically significant correlation between GSTT1 null genotype and lung cancer in Asian population was observed $\left(\mathrm{OR}=1.28,95 \% \mathrm{Cl}=1.10,1.49 ; \mathrm{P}_{\text {heterogeneity }}<0.001\right.$ and $\left.I^{2}=62.0 \%\right)$. Sub-group analysis revealed there was a statistically increased lung cancer risk in ever-smokers who carried the GSTT1 null genotype $\left(\mathrm{OR}=1.94,95 \% \mathrm{Cl}=1.27,2.96\right.$; $\mathrm{P}$ heterogeneity $=0.02$ and $\left.\mathrm{I}^{2}=58.1 \%\right)$. It was also indicated that GSTT1 null genotype could increase lung cancer risk among population-based studies $(\mathrm{OR}=1.25,95 \% \mathrm{Cl}=1.04,1.50$; $P_{\text {heterogeneity }}=0.003$ and $\left.\mathrm{I}^{2}=56.8 \%\right)$. The positive association was also found in studies of sample size ( $\leq 500$ participants) $\left(\mathrm{OR}=1.34,95 \% \mathrm{Cl}=1.10,1.62 ; \mathrm{P}_{\text {heterogeneity }}<0.001\right.$ and $\left.\mathrm{I}^{2}=65.4 \%\right)$.
\end{abstract}

Conclusions: These meta-analysis results suggest that GSTT1 null genotype is associated with a significantly increased risk of lung cancer in Asian population.

Citation: Yang X, Qiu M-T, Hu J-W, Wang X-x, Jiang F, et al. (2013) GSTT1 Null Genotype Contributes to Lung Cancer Risk in Asian Populations: A Meta-Analysis of 23 Studies. PLoS ONE 8(4): e62181. doi:10.1371/journal.pone.0062181

Editor: Michael Scheurer, Baylor College of Medicine, United States of America

Received January 8, 2013; Accepted March 18, 2013; Published April 24, 2013

Copyright: (C) 2013 Xu et al. This is an open-access article distributed under the terms of the Creative Commons Attribution License, which permits unrestricted use, distribution, and reproduction in any medium, provided the original author and source are credited.

Funding: This work was supported by the National Natural Science Foundation of China (81201830) and Natural Science Foundation of Jiangsu Province (BK2010589, BK2011857), China. The funders had no role in study design, data collection and analysis, decision to publish, or preparation of the manuscript.

Competing Interests: The authors have declared that no competing interests exist.

* E-mail: xulin83cn@gmail.com (LX); yinhero001@126.com (RY)

9 These authors contributed equally to this work.

\section{Introduction}

Lung cancer is the most common malignancy worldwide. It is a leading cause of cancer death in men and women in the United States [1]. In recent years, the incidence of lung cancer in Asia increased rapidly. It has become one of the greatest threats to human health. Tobacco smoking, family history and susceptible gene mutations are main risk factors of lung cancer. Recently, various gene polymorphisms contributing to lung cancer risk have been discovered, such as DNA repair genes family (XRCG1, hOGG1, XPD, XPA, XRCC3) [2,3,4,5,6], cytochrome P450 (CYP450) [7], glutathione S-transferases family (GSTs) [8], and MicroRNAs (miRNAs) [9,10,11].

GSTs contain a variety of function isozymes, which are involved in the metabolic detoxification of reactive electrophilic compounds [12]. The glutathione S-transferases (GSTs) family contains six members in human: $\operatorname{GSTA}(\alpha)$, GSTM $(\mu)$, GSTP $(\pi), \operatorname{GSTS}(\sigma)$, and GSTT $(\theta)[13,14]$. Glutathione S-transferase T1 (GSTT1) belongs to GSTT $(\theta)$, which has been identified in human liver. It is located on $22 \mathrm{q} 11.23$, and encodes a protein consisting of 240 amino acids. The length of GSTT1 gene is 8092bp with 5 exons and 4 introns [15]. The genotype of
GSTT1 allele homozygous deletion is GSTT1 null. In Asian population, the frequency of GSTT1 null genotype is higher compared with other population [16]. Recently, there are a number of published studies focusing on the relationship between GSTT1 null genotype and lung cancer risk. In 1996, Deakin first reported that GSTT1 null genotype was associated with an increased susceptibility to total ulcerative colitis, but was not increased in the lung, oral or gastric cancer cases [17]. Thereafter, a lot of studies have been carried out and yielded different or even controversial results. For example, some studies found that GSTT1 null genotype was associated with an increased risk for lung cancer in Asian population [18,19], while other studies reported negative results [20,21].

To determine the correlation between GSTT1 null genotype and lung cancer risk in Asian population, we performed this metaanalysis by summarizing reported case--control studies, calculating the estimate of overall lung cancer risk and evaluating influence of smoking status and histological types. 


\section{Methods}

\section{Literature Search Strategy}

Eligible case-control studies included in our analysis were extracted by electronic search of databases (PubMed, EMBASE) and manual search of references of relative articles and reviews. Search terms were keywords relating to the GSTT1 gene (e.g., "Glutathione S-transferaseT1", and "GSTT1") in combination with words related to lung cancer (e.g., "lung", combined with "cancer", "carcinoma", "tumor" or "neoplasms") and polymorphism or variation. The last research was performed on January 6 , 2013. All relevant reports identified were included with no restriction.

\section{Inclusion and Exclusion Criteria}

The major inclusion criteria were (a) case-control studies or cohort studies; (b) investigating the association between GSTT1 null genotype and lung cancer risk; (c) Asian population; (d) available genotype distribution information in cases and controls or odds ratio (OR) with its 95\% confidence intervals (CIs). The major reasons for exclusion of studies were (a) reviews and repeated literatures; (b) case-only studies; (c) studies without detail genotype frequencies.

\section{Data Extraction}

Data of eligible studies were extracted independently by two investigators and the following data were collected: name of first author, year of publication, country where the study was conducted, age, sex, histological types, source of control, number of cases and controls, genotype frequency in cases and controls. Histological types were classified as squamous cell carcinoma (SqCG), adenocarcinoma (AG), small cell carcinoma (SCG) and others. All eligible studies were defined as hospital-based (HB) or population-based (PB) according to the control source. The two investigators directly extracted genotype frequency or estimated odds ratio of the papers. Discrepancies were discussed among all authors until they reached consensus on each item.

\section{Statistical Analysis}

ORs with 95\% CIs were used to measure the strength of association of GSTT1 null genotype with lung cancer risk. The pooled ORs of GSTT1 null genotype mentioned above was compared with GSTT1 present genotype between cases and controls. A 95\% CI was used for statistical significance test and a 95\% CI without 1 for OR indicating a significant increased or reduced cancer risk. Sensitivity analyses were performed to identify individual study' effect on pooled results and test the reliability of results. The fixed effects model (Mantel-Haenszel method) was used when there was no significant heterogeneity; otherwise, the random-effects model (the Der Simonian and Laird method) was utilized [22]. Chi-square based $Q$ test was used to check the statistical heterogeneity between studies, and the heterogeneity was considered significant when $\mathrm{p}<0.10$ [23]. The quantity $\mathrm{I}^{2}$ presented variation in $\mathrm{OR}$ attributable to heterogeneity [24]. Stratification and meta-regression analyses were performed to explore the potential source of heterogeneity among studies. Publication bias was detected with Begg's funnel plot [25] and the Egger's linear regression test [26], and $\mathrm{p}<0.05$ was considered significant. All $\mathrm{P}$ values are two-sided. Statistical analyses were done with Stata (version 12.1; Stata Corp, College Station, Texas USA).

\section{Results}

\section{Characteristics of Studies}

As shown in Figure 1, a total of 23 studies [18-21,27-45] were identified according to inclusion and exclusion criteria. The 23 studies included 4065 cases and 5390 controls. The detailed characteristics of the eligible studies included in this meta-analysis are shown in Table 1.

\section{Meta-analysis Results}

We observed a statistically significant correlation between GSTT1 null genotype and lung cancer in Asian population $\left(\mathrm{OR}=1.28, \quad 95 \% \quad \mathrm{CI}=1.10, \quad 1.49 ; \quad \mathrm{P}_{\text {heterogeneity }}<0.001 \quad\right.$ and $\mathrm{I}^{2}=62.0 \%$, Figure 2). As shown in Table 2, we performed subgroup analyses to investigate the effects of source of controls, smoking status, histological types, and number of participants. We first calculated the pooled OR for the risk of GSTT1 null genotype stratified by source of controls. There was a statistically significant link between GSTT1 null genotype and lung cancer in population-based studies $\left(\mathrm{OR}=1.25,95 \% \mathrm{CI}=1.04,1.50 ; \mathrm{P}_{\text {heterogene- }}\right.$ ity $=0.003$ and $\mathrm{I}^{2}=56.8 \%$ ) but not in hospital-based studies $\left(\mathrm{OR}=1.20, \quad 95 \% \quad \mathrm{CI}=0.95, \quad 1.52 ; \quad \mathrm{P}_{\text {heterogeneity }}=0.001 \quad\right.$ and $\mathrm{I}^{2}=72.4 \%$ ) (Figure S1). When stratified by smoking status, there was a statistically increased lung cancer risk in ever-smokers $\left(\mathrm{OR}=1.94, \quad 95 \% \quad \mathrm{CI}=1.27, \quad 2.96 ; \quad \mathrm{P}_{\text {heterogeneity }}=0.02 \quad\right.$ and $\mathrm{I}^{2}=58.1 \%$ ), while we did not found any significant association in non-smokers $\left(\mathrm{OR}=1.39,95 \% \mathrm{CI}=0.90,2.14 ; \mathrm{P}_{\text {heterogene- }}\right.$ ity $=0.042$ and $\mathrm{I}^{2}=51.9 \%$, Figure 3$)$. In the sub-group analyses of "squamous cell carcinoma", "adenocarcinoma", and "small cell carcinoma", we did not found any significant correlation between GSTT1 null genotype and specific histological type of lung cancer

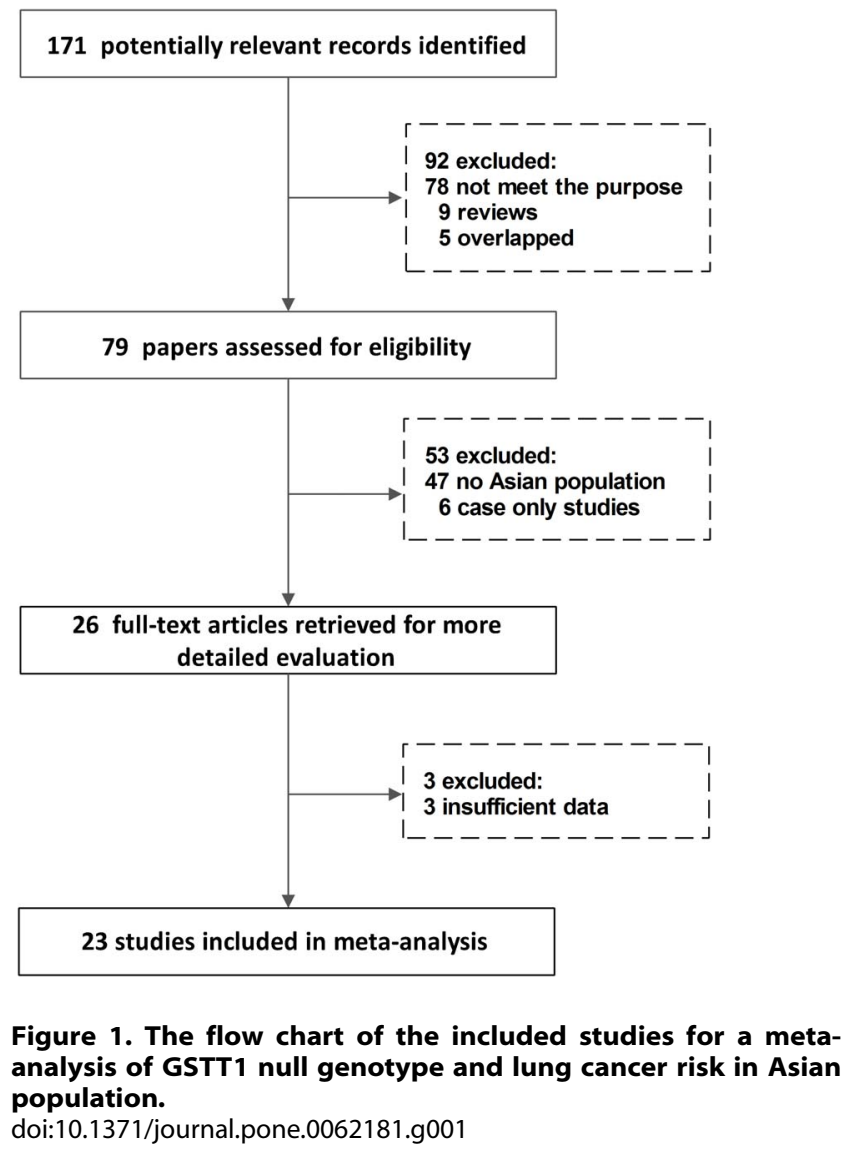




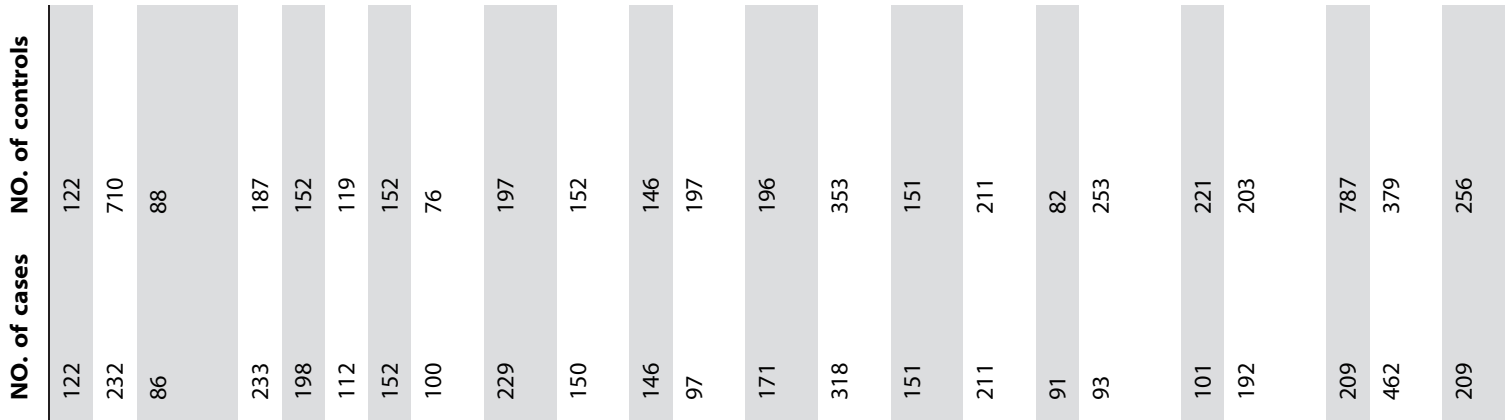

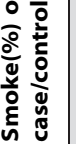
$\frac{1}{8}+\frac{1}{2}$

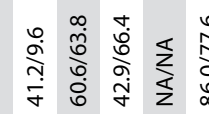

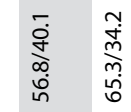

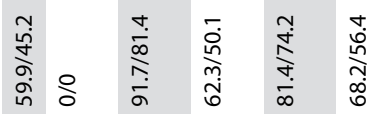

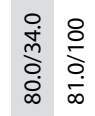

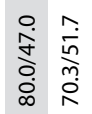

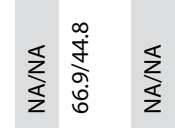

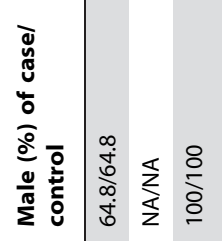

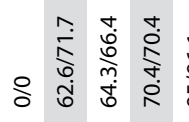



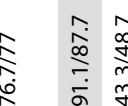

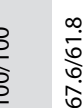

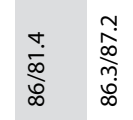

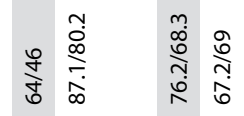

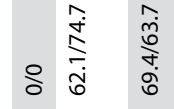

ฐั

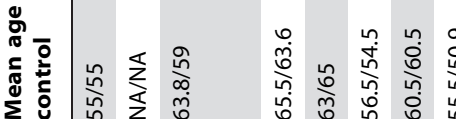

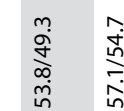

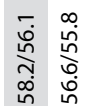

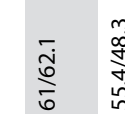

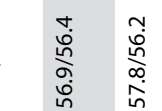

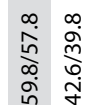

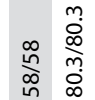

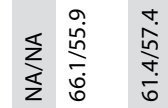

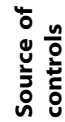

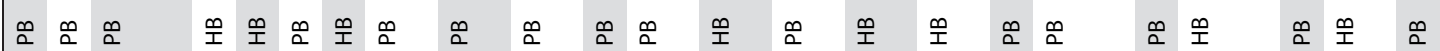

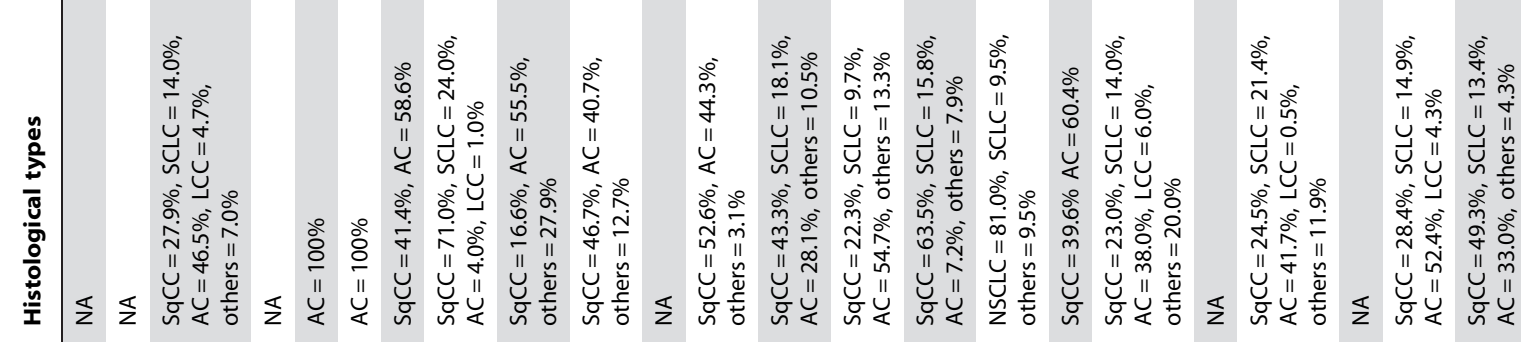

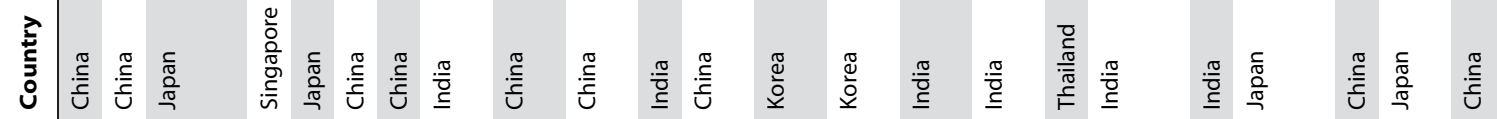
๘ 
risk (Figure S2). When restricting the analysis to number of participants, GSTT1 null genotype was significantly associated with lung cancer risk in studies of sample size ( $\leq 500$ participants), $\left(\mathrm{OR}=1.34, \quad 95 \% \quad \mathrm{CI}=1.10, \quad 1.62 ; \quad \mathrm{P}_{\text {heterogeneity }}<0.001 \quad\right.$ and $\left.\mathrm{I}^{2}=65.4 \%\right)$ but not in studies of sample size ( $>500$ participants) $\left(\mathrm{OR}=1.10, \quad 95 \% \quad \mathrm{CI}=0.95, \quad 1.28 ; \quad \mathrm{P}_{\text {heterogeneity }}=0.537 \quad\right.$ and $\mathrm{I}^{2}=0.0 \%$, Figure 2).

\section{Evaluation of Heterogeneity}

Table 2 showed the heterogeneity of studies in each comparison. In order to investigate the source of heterogeneity, we explored variables as source of controls, smoking status, histological types and sample size with meta-regression. Metaregression results revealed that histological types $(p=0.33)$, sample size $(p=0.26)$, source of control $(p=0.20)$, and smoking status $(p=0.38)$ did not contribute to the source of heterogeneity.

\section{Sensitivity Analyses and Publication Bias}

Sensitivity analysis was performed to assess the influence of each individual study on the pooled OR by deleting one single study each time, and there was no substantial change in the corresponding pooled OR (Figure S3). Begg's funnel plot and Egger's test were performed to assess publication bias. Begg's funnel plot was roughly symmetrical $(p=0.205$, Figure 4$)$. The statistical results still did not show publication bias by Egger's test $(\mathrm{p}=0.115)$. Therefore, there was no significant publication bias in these eligible studies.

\section{Discussion}

We performed this meta-analysis to explore the association of GSTT1 genotype with lung cancer in Asian population. In this meta-analysis, 23 eligible studies, including 4065 lung cancer cases and 5390 controls, were identified and analyzed. The results suggested that GSTT1 null genotype carriers had an increased risk of lung cancer in Asian population. This meta-analysis was based on all published data and had enough statistical power to detect a modest difference.

At present, many studies have investigated the association between GSTT1 null genotype and cancers, such as oral carcinoma [46], esophageal cancer [47], breast cancer [48], colorectal cancer [49], and pancreatic cancer [50], but the findings were inconsistent, especially in lung cancer. Further, about $20 \%$ of Caucasians are homozygous for a GSTT1 null allele. The GSTT1 null genotype is more common in Asians, in with the frequency ranges from $47 \%$ to $64 \%$ [51]. The GSTs can catalyze the conjugation of the tripeptide glutathione to a wide variety of exogenous and endogenous chemicals with electrophilic functional groups, including products of oxidative stress, environmental pollutants, and carcinogens [12]. GSTT1 null genotype lost this enzyme ability; therefore we speculated that GSTT1 null genotype could increase the risk of lung

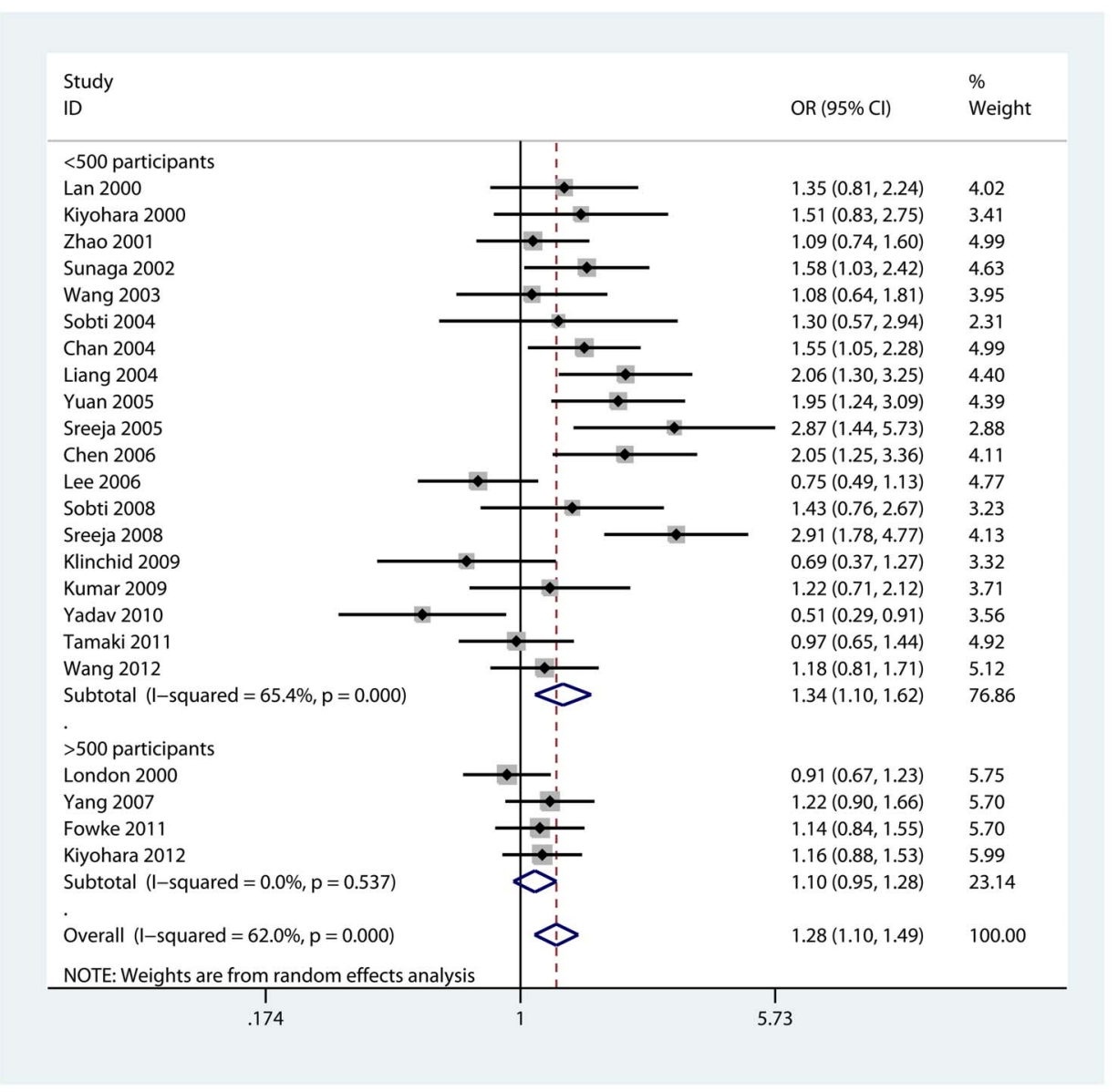

Figure 2. Forest plot for the association between GSTT1 null genotype and lung cancer risk in Asian population on stratification by sample size.

doi:10.1371/journal.pone.0062181.g002 
Table 2. Meta-analysis Results.

\begin{tabular}{|c|c|c|c|c|c|c|c|}
\hline \multirow[t]{2}{*}{ Characteristics } & \multirow[t]{2}{*}{$\mathbf{N}$} & \multirow[t]{2}{*}{ Case/control } & \multicolumn{2}{|c|}{ Heterogeneity test } & \multirow[t]{2}{*}{ OR(95\% Cl) } & \multirow{2}{*}{$P_{\text {Egger's test }}$} & \multirow{2}{*}{$P_{\text {Begg's tes }}$} \\
\hline & & & $1^{2}$ & $\mathbf{P}$ & & & \\
\hline Total & 23 & $4065 / 5390$ & $62.0 \%$ & $<0.001$ & $1.28(1.10,1.49)$ & 0.115 & 0.205 \\
\hline \multicolumn{8}{|l|}{ Source of controls } \\
\hline Population & 15 & $2295 / 3759$ & $56.8 \%$ & 0.003 & $1.25(1.04,1.50)$ & 0.262 & 0.428 \\
\hline Hospital & 7 & $1559 / 1420$ & $72.4 \%$ & 0.001 & $1.20(0.95,1.52)$ & 0.456 & 0.548 \\
\hline \multicolumn{8}{|l|}{ Smoking status } \\
\hline Ever-smoker & 8 & 792/579 & $58.1 \%$ & 0.02 & $1.94(1.27,2.96)$ & 0.972 & 0.902 \\
\hline Non-smoker & 8 & $448 / 711$ & $51.9 \%$ & 0.042 & $1.39(0.90,2.14)$ & 0.186 & 0.174 \\
\hline \multicolumn{8}{|l|}{ Histological types } \\
\hline SqCC & 7 & $395 / 617$ & $69.8 \%$ & 0.003 & $1.37(0.85,2.20)$ & 0.524 & 0.548 \\
\hline AC & 9 & $525 / 893$ & $66.1 \%$ & 0.003 & $1.26(0.89,1.78)$ & 0.616 & 0.466 \\
\hline SCLC & 3 & $138 / 285$ & $0.0 \%$ & 0.644 & $1.05(0.57,1.95)$ & 0.239 & 0.296 \\
\hline \multicolumn{8}{|l|}{ Sample size } \\
\hline$\leq 500$ participants & 19 & $2844 / 3161$ & $65.4 \%$ & $<0.001$ & $1.34(1.10,1.62)$ & 0.483 & 0.726 \\
\hline >500 participants & 4 & $1221 / 2229$ & $0.0 \%$ & 0.537 & $1.10(0.95,1.28)$ & 0.86 & 1 \\
\hline
\end{tabular}

SqCC: squamous cell carcinoma; AC: adenocarcinoma; SCLC: small cell carcinoma; P: $\mathrm{p}$ value for heterogeneity;

doi:10.1371/journal.pone.0062181.t002

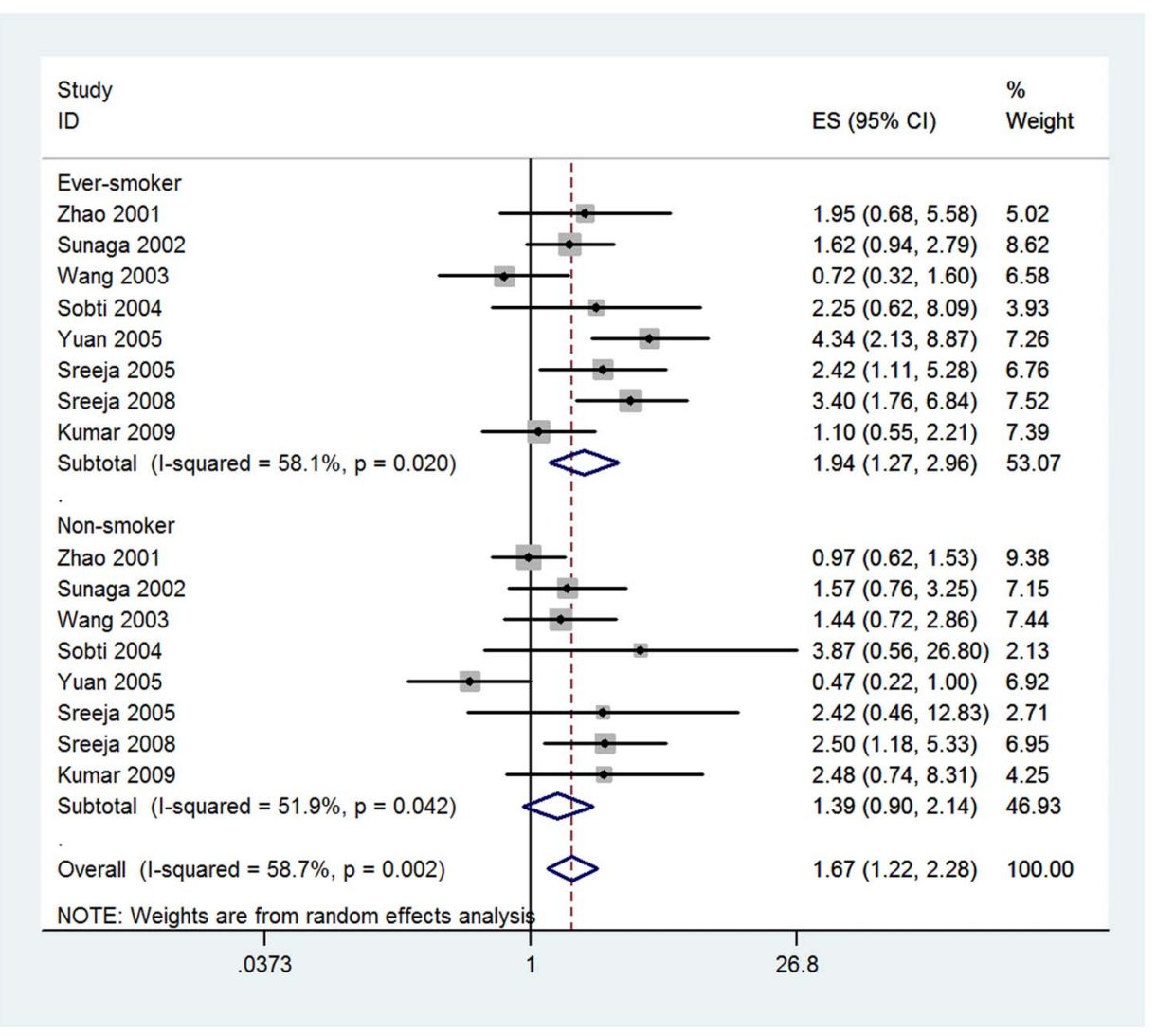

Figure 3. Forest plot for the association between GSTT1 null genotype and lung cancer risk in Asian population on stratification by smoking status.

doi:10.1371/journal.pone.0062181.g003 


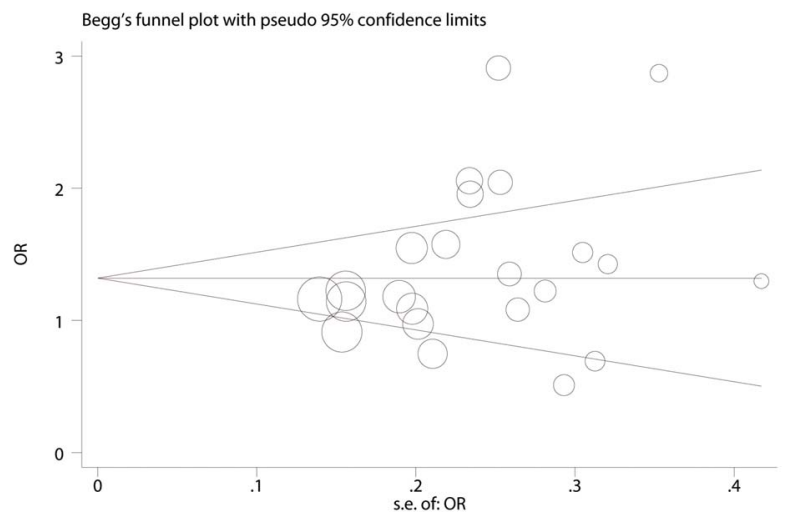

Figure 4. Funnel plot analysis of comparison to detect publication bias in $\mathbf{2 3}$ eligible studies. The circles represent the weight of individual study.

doi:10.1371/journal.pone.0062181.g004

cancer. However, in 23 eligible studies, only 8 reported positive results, which were in consistent with our pooled analysis. Furthermore, there was one study reported GSTT1 null genotype could decrease the lung cancer risk [40].

In the sub-group analysis of smoking status, there was a significant association in ever-smokers, while no association found in non-smokers. Cigarette smoking is a high risk factor of lung cancer. It may be related to the important role of GSTT1 deletion polymorphism in the metabolism of polycyclic aromatic hydrocarbons contained in cigarette smoking. In addition, in the subgroup of squamous cancer which was strongly associated with smoking, there was no significant association, although 2 individual studies reported GSTT1 null genotype increased lung cancer risk $[43,44]$. This discrepancy may be explained by the reason that the sample size of the studies was relatively small. No significant associations were found in the sub-group of adenocarcinoma and small cell carcinoma.

The heterogeneity was not detected by meta-regression. However, through sub-group analyses, we found the heterogeneity might come from source of controls and sample size. When studies were stratified by source of controls and sample size, we conducted heterogeneity test to explore the source of heterogeneity (Table 2). We also found the association between GSTT1 null genotype and lung cancer risk was more significant in the studies of population controls than hospital controls, which indicated that the distribution of GSTT1 null genotype in the hospital control groups might not represent of the general population. The pooled OR was mainly affected by studies of sample size ( $\leq 500$ participants). Studies of small size may contribute to a small-study effect, in which effects reported are larger, and lead to between studies

\section{References}

1. Siegel R, Naishadham D, Jemal A (2012) Cancer statistics, 2012. CA Cancer J Clin 62: 10-29.

2. David-Beabes GL, London SJ (2001) Genetic polymorphism of XRCC1 and lung cancer risk among African-Americans and Caucasians. Lung Cancer 34: 333-339.

3. Sugimura H, Kohno T, Wakai K, Nagura K, Genka K, et al. (1999) hOGG1 Ser326Cys polymorphism and lung cancer susceptibility. Cancer Epidemiol Biomarkers Prev 8: 669-674.

4. Gao WM, Romkes M, Day RD, Siegfried JM, Luketich JD, et al. (2003) Association of the DNA repair gene XPD Asp312Asn polymorphism with p53 gene mutations in tobacco-related non-small cell lung cancer. Carcinogenesis 24: 1671-1676.

5. Wu X, Zhao H, Wei Q Amos CI, Zhang K, et al. (2003) XPA polymorphism associated with reduced lung cancer risk and a modulating effect on nucleotide excision repair capacity. Carcinogenesis 24: 505-509. variance. Therefore, sample size was considered for heterogeneity in this meta-analysis. In addition, the overall number of subgroups such as "sample size $>500$ participants" and "hospital-based" studies was smaller compared with "sample size $\leq 500$ participants" and "population-based" studies respectively, so it could account for the lack of significant association.

In this meta-analysis, we included 4065 cancer cases and 5390 controls, which can provide enough statistical power and strengthened the reliability of our results. There are some limitations inherent in this meta-analysis. Firstly, individual data was not available and a more precise analysis should be conducted on other covariates such as age, sex, and environmental exposure. Secondly, the number of studies included for sub-group analysis of histological types and smoking status was small. Thirdly, the heterogeneity is difficult to exclude. It may be decided by confounding factors, such as gender, age, genetic diversities, different risk factors in life styles, and the exposure to different environmental factors which are difficult to collect completely.

In summary, this meta-analysis suggests that GSTT1 null genotype is associated with a significantly increased risk of lung cancer in Asian population. To confirm this result, large scale case-control studies with detailed individual information are required.

\section{Supporting Information}

Figure S1 Forest plot for the association between GSTT1 null genotype and lung cancer risk in Asian population on stratification by source of controls.

(TIF)

Figure S2 Forest plot for the association between GSTT1 null genotype and lung cancer risk in Asian population on stratification by histological types. $\mathrm{SqCC}$ : squamous cell carcinoma; AC: adenocarcinoma; SCLC: small cell carcinoma.

(TIF)

Figure S3 Sensitivity Analyses. The pooled odds ratios were calculated by omitting each data set at a time

(TIF)

Table S1 PRISMA checklist. (DOG)

\section{Author Contributions}

Conceived and designed the experiments: XY MQ RY FJ LX. Performed the experiments: XY MQJH XW. Analyzed the data: XY MQJH XW RY FJ LX. Contributed reagents/materials/analysis tools: XY MQ. Wrote the paper: XY MQ RY FJ.

6. Sun H, Qiao Y, Zhang X, Xu L, Jia X, et al. (2010) XRCC3 Thr241Met polymorphism with lung cancer and bladder cancer: a meta-analysis. Cancer Sci 101: $1777-1782$

7. Xu X, Kelsey KT, Wiencke JK, Wain JC, Christiani DC (1996) Cytochrome P450 CYP1A1 MspI polymorphism and lung cancer susceptibility. Cancer Epidemiol Biomarkers Prev 5: 687-692.

8. London SJ, Yuan JM, Chung FL, Gao YT, Coetzee GA, et al. (2000) Isothiocyanates, glutathione S-transferase M1 and T1 polymorphisms, and lungcancer risk: a prospective study of men in Shanghai, China. Lancet 356: 724 729.

9. Rotunno M, Zhao Y, Bergen AW, Koshiol J, Burdette L, et al. (2010) Inherited polymorphisms in the RNA-mediated interference machinery affect microRNA expression and lung cancer survival. Br J Cancer 103: 1870-1874. 
10. Megiorni F, Pizzuti A, Frati L (2011) Clinical Significance of MicroRNA Expression Profiles and Polymorphisms in Lung Cancer Development and Management. Patholog Res Int 2011: 780652.

11. Qiu MT, Hu JW, Ding XX, Yang X, Zhang Z, et al. (2012) Hsa-miR-499 rs3746444 Polymorphism Contributes to Cancer Risk: A Meta-Analysis of 12 Studies. PLOS ONE 7: e50887.

12. Hayes JD, Pulford DJ (1995) The glutathione S-transferase supergene family: regulation of GST and the contribution of the isoenzymes to cancer chemoprotection and drug resistance. Crit Rev Biochem Mol Biol 30: 445-600.

13. Mannervik B, Awasthi YC, Board PG, Hayes JD, Di IC, et al. (1992) Nomenclature for human glutathione transferases. Biochem J 282 (Pt 1): 305306.

14. Landi S (2000) Mammalian class theta GST and differential susceptibility to carcinogens: a review. Mutat Res 463: 247-283.

15. Juronen E, Tasa G, Uuskula M, Pooga M, Mikelsaar AV (1996) Purification, characterization and tissue distribution of human class theta glutathione Stransferase T1-1. Biochem Mol Biol Int 39: 21-29.

16. Shaikh RS, Amir M, Masood AI, Sohail A, Athar HU, et al. (2010) Frequency distribution of GSTM1 and GSTT1 null allele in Pakistani population and risk of disease incidence. Environ Toxicol Pharmacol 30: 76-79.

17. Deakin M, Elder J, Hendrickse C, Peckham D, Baldwin D, et al. (1996) Glutathione S-transferase GSTT1 genotypes and susceptibility to cancer: studies of interactions with GSTM1 in lung, oral, gastric and colorectal cancers. Carcinogenesis 17: 881-884.

18. Chan-Yeung M, Tan-Un KC, Ip MS, Tsang KW, Ho SP, et al. (2004) Lung cancer susceptibility and polymorphisms of glutathione-S-transferase genes in Hong Kong. Lung Cancer 45: 155-160.

19. Sunaga N, Kohno T, Yanagitani N, Sugimura H, Kunitoh H, et al. (2002) Contribution of the NQO1 and GSTT1 polymorphisms to lung adenocarcinoma susceptibility. Cancer Epidemiol Biomarkers Prev 11: 730-738.

20. Lan Q, He X, Costa DJ, Tian L, Rothman N, et al. (2000) Indoor coal combustion emissions, GSTM1 and GSTT1 genotypes, and lung cancer risk: a case-control study in Xuan Wei, China. Cancer Epidemiol Biomarkers Prev 9: 605-608.

21. Kiyohara C, Horiuchi T, Takayama K, Nakanishi Y (2012) Genetic polymorphisms involved in carcinogen metabolism and DNA repair and lung cancer risk in a Japanese population. J Thorac Oncol 7: 954-962.

22. Boissel JP, Sacks HS, Leizorovicz A, Blanchard J, Panak E, Peyrieux JC (1988) Meta-analysis of clinical trials: summary of an international conference. Eur J Clin Pharmacol 34: 535-538.

23. Lau J, Ioannidis JP, Schmid CH (1997) Quantitative synthesis in systematic reviews. Ann Intern Med 127: 820-826.

24. Higgins JP, Thompson SG, Deeks JJ, Altman DG (2003) Measuring inconsistency in meta-analyses. BMJ 327: 557-560.

25. Begg CB, Mazumdar M (1994) Operating characteristics of a rank correlation test for publication bias. Biometrics 50: 1088-1101.

26. Egger M, Davey SG, Schneider M, Minder C (1997) Bias in meta-analysis detected by a simple, graphical test. BMJ 315: 629-634.

27. Kiyohara G, Yamamura KI, Nakanishi Y, Takayama K, Hara N (2000) Polymorphism in GSTM1, GSTT1, and GSTP1 and Susceptibility to Lung Cancer in a Japanese Population. Asian Pac J Cancer Prev 1: 293-298.

28. Zhao B, Seow A, Lee EJ, Poh WT, Teh M, et al. (2001) Dietary isothiocyanates, glutathione S-transferase -M1, -T1 polymorphisms and lung cancer risk among Chinese women in Singapore. Cancer Epidemiol Biomarkers Prev 10: 10631067.

29. Wang J, Deng Y, Cheng J, Ding J, Tokudome S (2003) GST genetic polymorphisms and lung adenocarcinoma susceptibility in a Chinese population. Cancer Lett 201: 185-193.

30. Sobti RC, Sharma S, Joshi A, Jindal SK, Janmeja A (2004) Genetic polymorphism of the CYP1A1, CYP2E1, GSTM1 and GSTT1 genes and lung cancer susceptibility in a north indian population. Mol Cell Biochem 266: 1-9.

31. Chan-Yeung M, Tan-Un KC, Ip MS, Tsang KW, Ho SP, et al. (2004) Lung cancer susceptibility and polymorphisms of glutathione-S-transferase genes in Hong Kong. Lung Cancer 45: 155-160.

32. Sreeja L, Syamala V, Hariharan S, Madhavan J, Devan SC, et al. (2005) Possible risk modification by CYP1A1, GSTM1 and GSTT1 gene polymor- phisms in lung cancer susceptibility in a South Indian population. J Hum Genet 50: 618-627.

33. Chen HC, Cao YF, Hu WX, Liu XF, Liu OX, et al. (2006) Genetic polymorphisms of phase II metabolic enzymes and lung cancer susceptibility in a population of Central South China. Dis Markers 22: 141-152.

34. Lee KM, Kang D, Lee SJ, Park SK, Lee KH, et al. (2006) Interactive effect of genetic polymorphism of glutathione S-transferase M1 and smoking on squamous cell lung cancer risk in Korea. Oncol Rep 16: 1035-1039.

35. Yang M, Choi Y, Hwangbo B, Lee JS (2007) Combined effects of genetic polymorphisms in six selected genes on lung cancer susceptibility. Lung Cancer 57: $135-142$.

36. Sobti RC, Kaur P, Kaur S, Janmeja AK, Jindal SK, et al. (2008) Combined effect of GSTM1, GSTT1 and GSTP1 polymorphisms on histological subtypes of lung cancer. Biomarkers 13: 282-295.

37. Sreeja L, Syamala V, Hariharan S, Syamala VS, Raveendran PB, et al. (2008) Glutathione S-transferase M1, T1 and P1 polymorphisms: susceptibility and outcome in lung cancer patients. J Exp Ther Oncol 7: 73-85.

38. Klinchid J, Chewaskulyoung B, Saeteng S, Lertprasertsuke N, Kasinrerk W, et al. (2009) Effect of combined genetic polymorphisms on lung cancer risk in northern Thai women. Cancer Genet Cytogenet 195: 143-149.

39. Kumar M, Agarwal SK, Goel SK (2009) Lung cancer risk in north Indian population: role of genetic polymorphisms and smoking. Mol Cell Biochem 322: 73-79.

40. Yadav DS, Devi TR, Ihsan R, Mishra AK, Kaushal M, et al. (2010) Polymorphisms of glutathione-S-transferase genes and the risk of aerodigestive tract cancers in the Northeast Indian population. Genet Test Mol Biomarkers 14: 715-723.

41. Tamaki Y, Arai T, Sugimura H, Sasaki T, Honda M, et al. (2011) Association between cancer risk and drug-metabolizing enzyme gene (CYP2A6, CYP2A13, CYP4B1, SULT1A1, GSTM1, and GSTT1) polymorphisms in cases of lung cancer in Japan. Drug Metab Pharmacokinet 26: 516-522.

42. Fowke JH, Gao YT, Chow WH, Cai Q Shu XO, et al. (2011) Urinary isothiocyanate levels and lung cancer risk among non-smoking women: a prospective investigation. Lung Cancer 73: 18-24.

43. Liang GY, Pu YP, Yin LH (2004) [Studies of the genes related to lung cancer susceptibility in Nanjing Han population, China]. Yi Chuan 26: 584-588.

44. Yuan T, Zhou O, Zhu W, Guo Z, Li D, et al. (2005) Relationship between genetic polymorphism of GSTT1 gene and inherent susceptibility to lung cancer in Han population in Sichuan, China]. Zhongguo Fei Ai Za Zhi 8: 107-111.

45. Wang N, Wu Y, Zhou X, Wu Y (2012) [Association between genetic polymorphism of metabolizing enzymes and DNA repairing enzymes and the susceptibility of lung cancer in Henan population]. Wei Sheng Yan Jiu 41: 251256.

46. Mondal R, Ghosh SK, Talukdar FR, Laskar RS (2012) Association of mitochondrial D-loop mutations with GSTM1 and GSTT1 polymorphisms in oral carcinoma: A case control study from Northeast India.LID - S13688375(12)00351-X [pii]LID - 10.1016/j.oraloncology.2012.11.003 [doi]. Oral Oncol.

47. Abbas A, Delvinquiere K, Lechevrel M, Lebailly P, Gauduchon P, et al. (2004) GSTM1, GSTT1, GSTP1 and CYP1A1 genetic polymorphisms and susceptibility to esophageal cancer in a French population: different pattern of squamous cell carcinoma and adenocarcinoma. World J Gastroenterol 10: 3389-3393.

48. Bailey LR, Roodi N, Verrier CS, Yee CJ, Dupont WD, Parl FF (1998) Breast cancer and CYPIA1, GSTM1, and GSTT1 polymorphisms: evidence of a lack of association in Caucasians and African Americans. Cancer Res 58: 65-70.

49. Gertig DM, Stampfer M, Haiman C, Hennekens CH, Kelsey K, Hunter DJ (1998) Glutathione S-transferase GSTM1 and GSTT1 polymorphisms and colorectal cancer risk: a prospective study. Cancer Epidemiol Biomarkers Prev 7: 1001-1005.

50. Liu G, Ghadirian P, Vesprini D, Hamel N, Paradis AJ, et al. (2000) Polymorphisms in GSTM1, GSTT1 and CYP1A1 and risk of pancreatic adenocarcinoma. Br J Cancer 82: 1646-1649.

51. Parl FF (2005) Glutathione S-transferase genotypes and cancer risk. Cancer Lett 221: $123-129$ 